\title{
The Application of X-Ray Photoelectron Spectroscopy in Understanding Corrosion Mechanisms of Magnesium and Mg-Al Alloys
}

\author{
Sebastián Feliu Jr., ${ }^{*}$, C. Maffiotte ${ }^{2}$, Juan Carlos Galván ${ }^{1}$, Angel Pardo ${ }^{3}$, Maria Concepción Merino ${ }^{3}$ \\ and Raul Arrabal ${ }^{3}$
}

\author{
${ }^{I}$ Centro Nacional de Investigaciones Metalúrgicas CSIC, Avda. Gregorio del Amo 8, 28040 Madrid, Spain \\ ${ }^{2}$ CIEMAT. FNL (Edificio 2), Avda. Complutense, 22, 28040 Madrid, Spain \\ ${ }^{3}$ Departamento de Ciencia de Materiales, Facultad de Química, Universidad Complutense, 28040 Madrid, Spain
}

\begin{abstract}
The authors present a review of their research work on the application of X-ray photoelectron spectroscopy (XPS) to characterise thin $(\sim 3 \mathrm{~nm})$ natural oxide films that spontaneously form on the surface of magnesium and its alloys in contact with the oxygen in air, and thick $(>1 \mu \mathrm{m})$ corrosion films rich in carbonates and other species that form during exposure to a humid atmosphere. The results obtained can provide much useful information about the protection mechanisms of these materials. Emphasis is placed on the relationship between the alloy's Al content and the characteristics of the natural oxide film and the relationship between segregation of calcium impurities from the bulk to the outer surface of the metal and repercussions on electrochemical behaviour. The natural oxide film may alone be sufficiently protective in less aggressive environments, making it of interest to know its characteristics. A detailed study will also be made of the changes in chemical composition that may occur in this passivating film with increasing exposure time to a humid atmosphere, deteriorating or reinforcing its anticorrosive properties. In particular, an attempt will be made to research the effect on corrosion behaviour of: (a) the time the different specimens are exposed to the aggressive agent (humid atmosphere); (b) the possible formation during corrosive attack of layers that are rich in carbonates and other species; and (c) the presence of aluminium (alloying element) on the protective properties of the corrosion layers.
\end{abstract}

Keywords: XPS, surface chemistry, corrosion and magnesium alloys.

\section{INTRODUCTION}

This study focuses on Mg-Al alloys, a material that has aroused great scientific and technical interest in the last two decades. From a practical point of view, magnesium is the structural metal of the lowest density, which makes it highly attractive for use in the automotive, aerospace, IT and other industries where weight plays a decisive role. However, magnesium is also one of the most chemically active metals, and its corrosion resistance is one of the key limits to its use in service. From a scientific point of view this is an issue of great current relevance, as is witnessed by the choice of $\mathrm{Mg}$ alloys as one of the four research fronts within the field of corrosion by the prestigious ISI Web of Knowledge scientific database in its 2008 version.

Mg-Al alloys, and in particular those containing 8-10\% $\mathrm{Al}$, are among the most corrosion resistant magnesium alloys. The effect of aluminium as an alloying element on the corrosion resistance of magnesium has been studied by many authors in a wide range of experimental conditions: exposure to dry oxygen $[1,2]$; to environmental atmospheres [3-5], to atmospheres with a high degree of humidity [6-10]; in immersion in distilled water [11]; in saline solutions or

*Address correspondence to this author at the Centro Nacional de Investigaciones Metalúrgicas CSIC, Avda. Gregorio del Amo 8, 28040 Madrid, Spain; Tel: +34-91-5538900; Fax: +34-91-5347425;

E-mail: sfeliu@cenim.csic.es atmospheres [12-28], etc. In Mg-Al alloys the greater affinity of aluminium for oxygen tends to produce passivating films of aluminium oxides or mixtures of $\mathrm{Mg}$ and $\mathrm{Al}$ oxides, making the exposed surface especially stable [14, 17-19]. The literature has paid particular attention to the effect of $\beta$ phase $\left(\mathrm{Mg}_{17} \mathrm{Al}_{12}\right)$ precipitates in $\mathrm{Mg}-\mathrm{Al}$ alloys, which can act as a barrier to inhibit the corrosion process $[9,14,20,21]$. This effect is typical in alloys with high aluminium contents (e.g. $\sim 9 \mathrm{wt} \% \mathrm{Al}$ ), like the highly studied AZ91 alloy [2, 9, $10,13,20,21]$.

Many researchers have studied the relationship between the microstructure of the alloy (amount and distribution of $\beta$ phase precipitates), or the Al content in the bulk alloy, and its corrosion resistance [9-29]. Fewer researchers have considered the chemical composition of the thin passivating films on the outer surface of the alloy (thickness of the order of $3 \mathrm{~nm}$ ) which form in contact with the atmosphere or in solutions of low aggressivity $[1-6,30,31]$. The performance of a particular material is often controlled by the protective qualities of the surface oxide which forms [32]. This study presents the highly promising results obtained with the XPS technique, which allows the analysed thickness to be reduced to only $3 \mathrm{~nm}$ and supplies information on the oxidation state of the detected element. This capacity means that this technique can provide useful information on the nature and composition of passive oxide films, allowing a better understanding of the corrosion process that takes place at an atomic scale [32]. 
Electrochemical methods, and in particular electrochemical impedance spectroscopy (EIS), have been shown in innumerable studies to be an efficient and convincing tool for studying the corrosion behaviour of metals. Their most outstanding and well-known advantages are that they allow continuous monitoring of the progress of corrosion, with instantaneous measurements of the corrosion rate, and can provide information on the reactions and mechanisms of electrochemical deterioration. However, when this technique is used to study the progress of the corrosion of complex materials of special technological interest, such as magnesium alloys, limitations and complications are encountered when it comes to interpreting the various arcs plotted in the impedance diagrams and the evolution of the electrochemical parameters deduced from these with time. Given that EIS and XPS are two techniques which provide information on the surface of the material, this research has attempted to use them to interpret the behaviour of magnesium alloys. EIS measurements in a saline solution have been used to verify the protective character of the products previously analysed by XPS on the surface of the material after its exposure to the humidity test.

The passivating films that form spontaneously on the surface of magnesium in contact with the air seem to be comprised mainly by mixtures of $\mathrm{MgO}$ and $\mathrm{Mg}(\mathrm{OH})_{2}$ [30]. In the case of $\mathrm{Mg}$-Al alloys, besides the presence of magnesium oxides/hydroxides we have also observed strong Al segregation towards the outer surface, probably due to the alloy manufacturing process. The $\mathrm{Al}$ concentration can increase by a factor of 2-3. The surface enrichment of this element (which appears in the form of $\mathrm{Al}_{2} \mathrm{O}_{3}$ ) is around 15 wt $\%$ for $\mathrm{Mg}-\mathrm{Al}$ alloys with aluminium contents of 2 to 10 wt.\% in the bulk analysis.

During the exposure of pure magnesium to the air the thin magnesium oxide/hydroxide film reacts with atmospheric $\mathrm{CO}_{2}$ to form magnesium carbonate, which tends to reduce the attack of the material. In a previous study [30] it was observed that as the aluminium content in the bulk alloy rises, so the magnesium carbonate content increases and the $\mathrm{MgO}$ and $\mathrm{Mg}(\mathrm{OH})_{2}$ content on the alloy surface decreases for similar atmospheric exposure times. On the surface of AZ91D and AZ80 alloys, XPS data suggested similar magnesium carbonate contents to the $\mathrm{Mg}$ oxide or hydroxide contents. In subsequent exposure to the humidity cabinet, an important effect of the aluminium alloying content was seen on the corrosion rate, which tends to decrease significantly as the Al content increases. An inverse correlation was seen between the carbonate percentage formed as a result of atmospheric exposure and subsequent corrosion in the humidity condensation test. It seems likely that the aluminium atoms found in solid solution in the bulk alloy play a decisive role in both phenomena [30].

In another previous study [31], assessing AZ31 alloy in humidity condensation tests, an important reduction in corrosion was measured compared to that experienced by a pure $\mathrm{Mg}$ reference specimen. Practically all of the aluminium content in the AZ31 alloy (3 wt\%) is in solid solution, and thus the beneficial effect of this alloying element cannot be explained in terms of microstructural changes. Furthermore, no passivating aluminium oxide enrichment of the resulting corrosion layers was observed. However, what was seen was that the magnesium oxide signal persisted throughout the testing time in the case of the AZ31 alloy surface but not with the pure $\mathrm{Mg}$. In this case the greater chemical stability of the oxide/hydroxide film formed on the AZ31 alloy than that formed on the $\mathrm{Mg}$ results in significantly lower corrosion of the former in exposure to testing in a humid atmosphere.

In this paper the authors present a review of their research work over the last three years on the application of the XPS technique to clarify how different parameters may affect the protection mechanisms of magnesium and $\mathrm{Mg}-\mathrm{Al}$ alloys. Most of the experimental information and results has been taken from published works by the authors [30, 31]. On the following pages, information is presented in relation with the following points:

(a) Thickness determination of the natural oxide film that forms spontaneously on the surface of magnesium and Mg-Al alloys. Effect of the presence of alloying elements on the thickness of this layer.

(b) Segregation of impurities contained in the bulk material to the surface and their influence on the protective properties of the outer surface.

(c) Study of the changes that can take place in the chemical composition of the natural oxide film with exposure time, deteriorating or reinforcing its anticorrosive properties.

\section{EXPERIMENTAL}

\subsection{Test Materials}

The chemical composition of the tested magnesium alloys, namely AZ31, AZ61, AZ80 and AZ91D, are listed in Table 1. Unalloyed commercially pure $\mathrm{Mg}$ was used as the reference material. Pure $\mathrm{Mg}$ and AZ31 and AZ61 alloys were manufactured in wrought condition, whereas AZ80 and AZ91D alloys were manufactured by a casting process. All the materials were supplied by Magnesium Elektron Ltd.

\subsection{Humidity Test}

The tests were carried out in a high relative humidity environment of $98 \%$ at $35^{\circ} \mathrm{C}$ for 30 days, simulated by a CCK 300 climate cabinet (Dycometal).

\subsection{EIS Measurements}

Electrochemical impedance spectroscopy (EIS) was used to obtain charge transfer resistance values after 1 hour of immersion in $0.005 \mathrm{M} \mathrm{NaCl}$ for the materials in unexposed condition and after exposure to the humidity condensation test. This low aggressivity solution was selected due to the exceptionally high corrosion rate of the pure magnesium specimen, which is attacked and disintegrates in just a few days of testing in 3\% $\mathrm{NaCl}$. An AUTOLAB potentiostat, model PGSTAT30, with Frequency Response Analyser (FRA) software was used. The frequency ranged from 100 $\mathrm{kHz}$ to $1 \mathrm{mHz}$ with 5 points/decade, whereas the amplitude of the sinusoidal potential signal was $10 \mathrm{mV}$ with respect to the open circuit potential, OCP. A three-electrode set-up was employed: $\mathrm{Ag} / \mathrm{AgCl}$ and graphite were used as reference and counter electrodes, respectively, and the working electrode was the material under study with an immersed area of 1 $\mathrm{cm}^{2}$. 
Table 1. Chemical Composition of Pure Mg and of the Mg-Al Alloys

\begin{tabular}{|c|c|c|c|c|c|c|c|c|c|c|}
\hline Material & Al & Zn & Mn & Si & Cu & Fe & Ni & Ca & Zr & Others \\
\hline \hline Mg (99\%) & 0.006 & 0.014 & 0.03 & 0.019 & 0.001 & 0.004 & $<0.001$ & 0.0026 & \\
\hline AZ31 & 3.1 & 0.73 & 0.25 & 0.02 & $<0.001$ & 0.005 & $<0.001$ & 0.0014 & $<0.001$ & $<0.30$ \\
\hline AZ61 & 6.2 & 0.74 & 0.23 & 0.04 & $<0.001$ & 0.004 & 0.001 & 0.0013 & $<0.001$ & $<0.30$ \\
\hline AZ80 & 8.2 & 0.46 & 0.13 & 0.01 & $<0.001$ & 0.004 & & 0.0013 & $<0.30$ \\
\hline AZ91D & 8.8 & 0.68 & 0.30 & 0.01 & $<0.001$ & 0.004 & $<0.008$ & 0.0014 & $<0.30$ \\
\hline
\end{tabular}

\subsection{Surface Analysis}

Photoelectron spectra were acquired using a Fisons MT500 spectrometer equipped with a hemispherical electron analyser (CLAM 2) and an Mg K $\alpha$ X-ray source operated at $300 \mathrm{~W}$. The specimens were mechanically fixed on small flat discs supported on an XYZ manipulator placed in the analysis cabinet. The residual pressure in this ion-pumped analysis cabinet was maintained below $10^{-8}$ Torr during data acquisition. Spectra were collected for 20-90 min, depending on the peak intensities at a pass energy of $20 \mathrm{eV}$, which is typical of high-resolution conditions. The intensities were estimated by calculating the area under each peak after smoothing and subtraction of the S-shaped background and fitting the experimental curve to a mix of Lorentzian and Gaussian lines of variable proportion. Although specimen charging was observed, accurate binding energies (BE) could be determined by referencing to the adventitious $\mathrm{C} 1 \mathrm{~s}$ peak at $285.0 \mathrm{eV}$. Atomic ratios were computed from peak intensity ratios and reported atomic sensitivity factors [33].

For the acquisition of concentration profiles (distribution of elements as a function of specimen thickness) the surface was sputtered by argon ion bombardment (AIB). Bombardment was performed using an EXO5 ion gun incorporated into the equipment, provided with a scanning unit to track the beam, and operating at a voltage of $5 \mathrm{kV}$, an intensity of $10 \mathrm{~mA}$ and a pressure of $1 \times 10^{-7}$ Torr. The specimen current was $1 \mu \mathrm{A}$ during bombardment. As it will be commented later, this current was equivalent to a sputtering rate of about $0.15 \mathrm{~nm} / \mathrm{min}$.

\section{RESULTS AND DISCUSSION}

3.1. Information on Characteristics of the Natural Oxide Film Formed on the Surface of Magnesium and Mg-Al Alloys

\subsubsection{Thickness Determination of the Natural Oxide Film Formed in Contact with the Air}

High-resolution O1s spectra of the oxide films formed spontaneously on pure magnesium and $\mathrm{Mg}$ - $\mathrm{Al}$ alloys are presented in Fig. (1a-m). The spectra obtained on the original surface (Fig. 1a-e) are fairly similar, containing one single component at a binding energy of $532.2 \mathrm{eV}$ associated with the presence of oxygen in hydroxide form [1,3]. Fig. (1f, j) show the spectra obtained after 10 minutes of sputtering. These spectra show the most intense component at a binding energy of $531.2 \mathrm{eV}$ associated with the presence of oxygen in the form of magnesium oxide, $\mathrm{MgO}$ [34] and another less intense component at a binding energy of 533.2 $\mathrm{eV}$ which may be attributed to the presence of oxygen in
$\mathrm{Al}_{2} \mathrm{O}_{3}$ or hydroxide groups not eliminated by the sputtering. The O1s spectra obtained after 20 minutes of sputtering (Fig. 1k-m) were similar to those acquired after 10 minutes (Fig. 1h-j).

The evolution with argon ion bombardment time of the $\mathrm{Mg} 2 \mathrm{p}$ high resolution XPS spectra obtained on the oxide films formed spontaneously on pure magnesium and $\mathrm{Mg}-\mathrm{Al}$ alloys is presented in Fig. (2a-m). The spectra obtained on the original surface (Fig. 2a-e) are fairly similar, containing one single component at a binding energy of $50.8 \mathrm{eV}$ associated with the presence of magnesium in hydroxide form [34]. Fig. (2f-j) show the spectra obtained after 10 minutes of AIB. On the pure Mg (Fig. 2f) and AZ31 (Fig. 2g) surfaces these spectra show the most intense component at a binding energy of $48.6 \mathrm{eV}$ associated with the presence of magnesium in metallic state and another less intense component at a binding energy of $50.8 \mathrm{eV}$ which may be attributed to the presence of magnesium in oxide form. It is interesting to note the considerably lower intensity of the metallic magnesium signal on the AZ61 (Fig. 2h), AZ80 (Fig. 2i) and AZ91D (Fig. 2j) specimens than on the pure Mg (Fig. 2f) and AZ31 (Fig. 2g) specimens. This data is interpreted as being due to the greater thickness of the natural oxide film on the surface of the first three alloys in contact with oxygen in the air.

The thickness of the natural oxide film on the surface of the magnesium specimens was calculated using the expression given by Strohmeier [35]:

$\mathrm{d}_{\mathrm{o}}(\mathrm{nm})=\lambda_{\text {oxide }} \sin \theta \ln \left[\mathrm{I}_{\text {oxide }} \mathrm{x} \lambda_{\text {metal }} \mathrm{x} \mathrm{N}_{\text {metal }}\right) /\left(\mathrm{I}_{\text {metal }} \times \lambda_{\text {oxide }} \mathrm{X}\right.$ $\left.\left.\mathrm{N}_{\text {oxide }}\right)+1\right]$

where $d_{o}$ is the thickness of the magnesium oxide layer (in $\mathrm{nm}) ; \theta$ is the photoelectron output angle $\left(45^{\circ}\right) ; \mathrm{I}_{\text {metal }}$ and $\mathrm{I}_{\text {oxide }}$ are the intensities of the magnesium components in metallic state and as oxide from the Mg $2 p$ peak (Fig. $2 \mathbf{f}-\mathbf{m}$ ); $\lambda_{\text {metal }}$ and $\lambda_{\text {oxide }}$ are the mean free paths of photoelectrons in the substrate and the oxide layer; and $\mathrm{N}_{\text {metal }}$ and $\mathrm{N}_{\text {oxide }}$ are the volume densities of magnesium atoms in metal and oxide [36]. The values of $\lambda_{\text {metal }}$ and $\lambda_{\text {oxide }}$ are 3.0 [37] and $2.6 \mathrm{~nm}$ [38], respectively [39], and an $\mathrm{N}_{\text {metal }} / \mathrm{N}_{\text {oxide }}$ ratio of 1.0 was used [40]. On the pure $\mathrm{Mg}$ and the AZ31 alloy an important increase was observed in the intensity of the $\mathrm{Mg}^{0}$ signal after 10 minutes of AIB (Fig. 2f, g). However, the fact that the intensity of the component associated with metallic magnesium ( $\mathrm{I}_{\text {metal }}$ ) is practically negligible on AZ61, AZ80 and AZ91D after 10 minutes of AIB (Fig. 2h-j) implies a problem for the thickness determination of the surface oxide layers. The sputtering rate can be estimated by the above equation when the metallic $\mathrm{Mg}$ emerges after a certain 
O1s peak

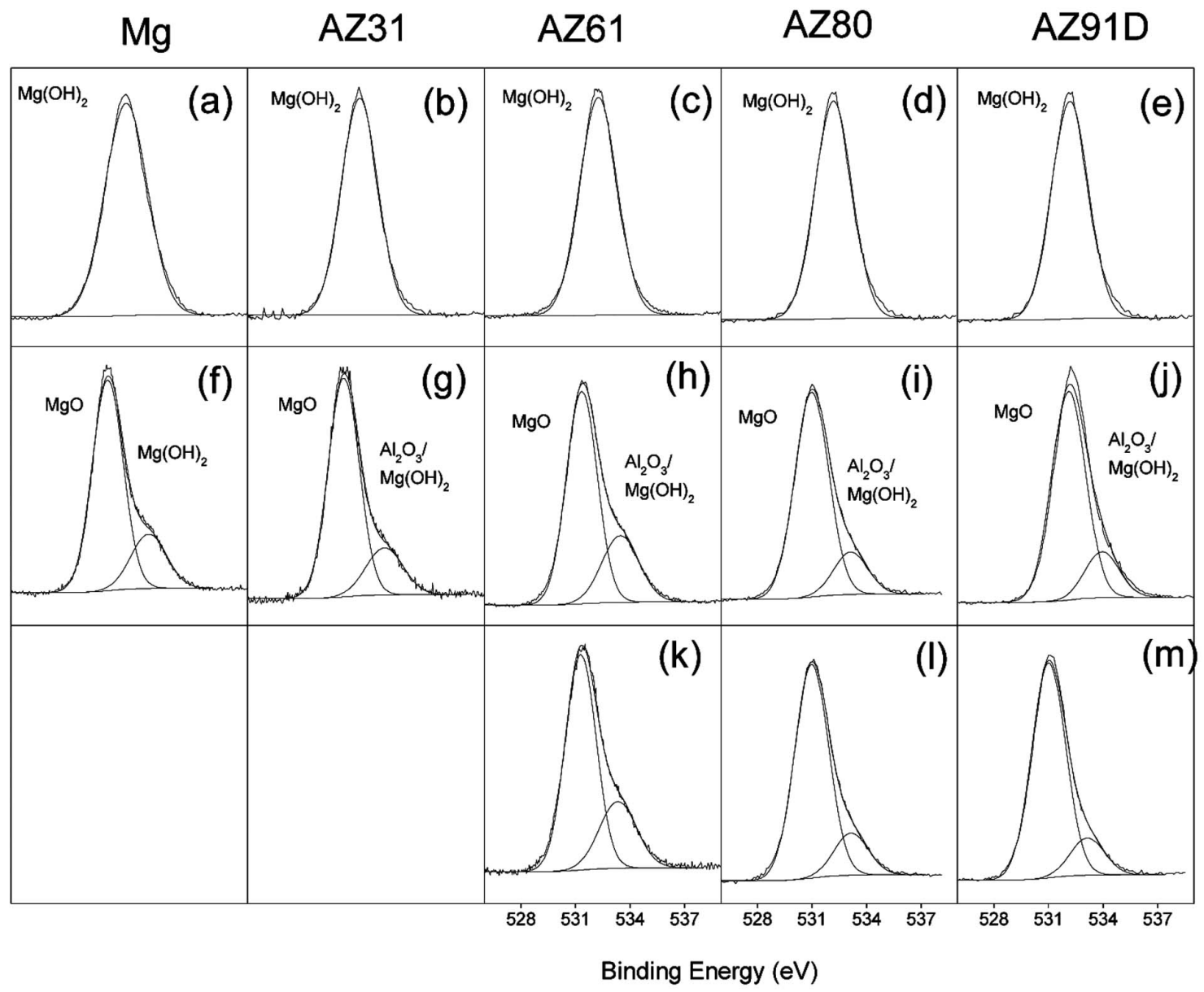

Fig. (1). Evolution of $\mathrm{O} 1 \mathrm{~s}$ high resolution XPS spectra obtained on the oxide film formed spontaneously on pure $\mathrm{Mg}$ and on Mg-Al alloys with argon ion bombardment time.

sputtering time (Fig. 2k-m) [34]. The sputtering rate of the natural oxide films for $\mathrm{Mg}$ and $\mathrm{Mg}$ alloys is about 0.15 $\mathrm{nm} / \mathrm{min}$. This value is close to the sputtering rates obtained by [34] for $\mathrm{Mg}$ in air and previous results by the authors on interstitial-free (IF) steels [41]. Fig. (2f, g, k-m) show the oxide layer thickness values calculated from the above equation plus the bombardment time necessary for a significant metallic magnesium component to appear in the Mg2p peak (Fig. 2f, g, k-m)) multiplied by the sputtering rate. The values obtained are similar to those observed in the literature $[3,4,42]$. It is interesting to note that the thickness of the spontaneous oxide film on alloys AZ61 (Fig. 2k), AZ80 (Fig. 2l) and AZ91D (Fig. 2m) is approximately twice that observed on the pure Mg (Fig. 2f) and AZ31 (Fig. 2g) specimens. These results show a certain similitude to those observed by Splinter and McIntyre [6], who found that the rate of oxide nucleation and growth is enhanced on $\mathrm{Mg}-\mathrm{Al}$ surfaces compared to pure Mg surfaces, especially at higher Al contents. Moreover, the natural oxide film thickness on AZ80 (Fig. 2l) is greater than that observed on AZ61 (Fig. 2k) and AZ91D (Fig. 2m). Another paper currently in preparation will clearly show a tendency for the $R_{t}$ values to rise and the corrosion rate values to drop as the natural oxide film thickness $\left(\mathrm{d}_{\text {oxide }}\right)$ determined by XPS increases.

\subsubsection{Effect of Surface Heterogeneities on the Thickness of the Oxide Layer Formed Spontaneously in Contact with the Air}

Thickness differences (of $\mathrm{nm}$ order) in the oxide layer that forms spontaneously on the surface of metallic materials have been related with the presence of imperfections or heterogeneities where the film is more pervious to the movement of the reaction products $[4,6,43,44]$. On the commercial magnesium alloys tested in this work there also seems to be direct correspondence between the thickness of the natural oxide film and the microstructural complexity of the surface upon which it is formed. Fig. (3) shows a very significant presence of $\beta$ intermetallic phase on the AZ80 (Fig. 3d) and AZ91D (Fig. 3e) alloy surfaces. In contrast with its absence on alloy AZ31 (Fig. 3b) and pure Mg (Fig. 3a). Chill casting promoted a biphasic microstructure in the AZ80 alloy, with an $\alpha-\mathrm{Mg}$ solid solution and discontinuous precipitation of $\beta$-phase $\left(\mathrm{Mg}_{17} \mathrm{Al}_{12}\right)$ in lamellar form (Fig. 3d). On the other hand, the ingot casting process produced a coarse eutectic dendritic microstructure in the AZ91D alloy and a lower percentage of the magnesium surface coated by intermetallic phases (Fig. 3e) [16]. 


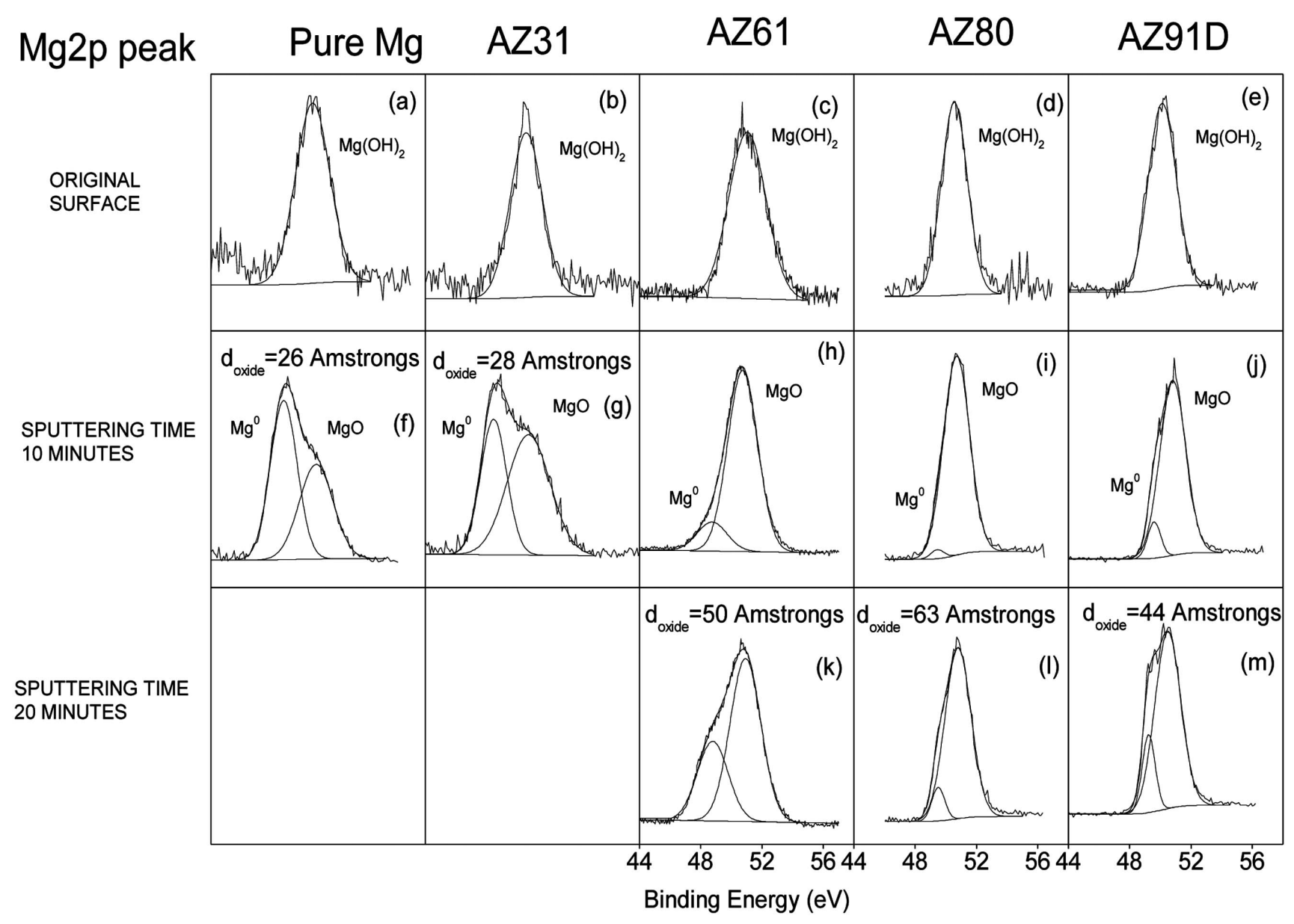

Fig. (2). Evolution of Mg2p high resolution XPS spectra obtained on the oxide film formed spontaneously on pure $\mathrm{Mg}$ and on Mg-Al alloys with argon ion bombardment time.

\subsubsection{Segregation of Impurities from the Bulk Material to the Outer Surface}

Many papers have reported impurity element segregation at or near the surface of magnesium and magnesium alloys as a result of the casting process. When minor contaminant elements $(\mathrm{Fe}, \mathrm{Ni}$ and $\mathrm{Cu}$ ) exceed their solubility limit they precipitate at the surface as intermetallic phases, where they may act as a galvanic cathode and accelerate the corrosion process of the alloy [26, 29]. In contrast to other impurities, and despite the fact that calcium is one of the commonest contaminants in many metals, no references have been found to superficial calcium enrichment on magnesium or magnesium alloys as a consequence of the casting process. The greatest setback to obtaining information on this phenomenon is that the segregation of $\mathrm{Ca}$ impurities (few $\mathrm{ppm}$ ) to the surface takes place in very thin layers (one monolayer), so thin that it is often inappreciable by conventional materials characterisation techniques (SEM/ EDX or TEM) [45]. In the present study highly promising results have been obtained with the XPS technique.

Table 2 compares the $\mathrm{Ca} /(\mathrm{Ca}+\mathrm{Mg})$ atomic ratios obtained in the bulk of pure $\mathrm{Mg}$ and $\mathrm{Mg}-\mathrm{Al}$ alloys by chemical analysis and on the outer surface by XPS. Attention is drawn to the presence of significant amounts of $\mathrm{Ca}$ on the surface of all the studied alloys. The atomic fraction of $\mathrm{Ca}$ segregated to the surface is almost 1500 times the atomic fraction in the bulk. The $\mathrm{Ca} /(\mathrm{Ca}+\mathrm{Mg})$ atomic ratios obtained by XPS on the surface of the pure magnesium reach values close to 0.28 , which could mean that calcium covers approximately one third of the surface. XPS analysis of the outer surface of pure $\mathrm{Mg}$ shows twice as much calcium content as that observed on the surface of the AZ31, AZ61 and AZ80 and AZ91D alloys. This proportion observed on the surface coincides practically with that identified in the bulk of these materials (Table 1). It seems likely that the observed superficial calcium enrichment has come from the calcium contained as an impurity in the bulk alloy. It is notable that other alloying elements such as $\mathrm{Zn}, \mathrm{Mn}$ and $\mathrm{Si}$, with a higher content in the bulk material, are not encountered on the surface of the studied alloys (Table 1).

Fig. (4) shows the evolution of Ca2p high resolution XPS spectra observed on the pure $\mathrm{Mg}$ surface with AIB time. These spectra are representative of the $\mathrm{Ca} 2 \mathrm{p}$ spectra observed on the surface of the other materials. The $\mathrm{Ca} 2 \mathrm{p}$ high resolution spectrum contains a single doublet with a binding energy of $347.0 \mathrm{eV}$ (Fig. 4). This binding energy is typical of $\mathrm{Ca}$ as $\mathrm{Ca}^{2+}[46]$. Therefore, the significant $\mathrm{Ca}$ content observed by XPS on the surface of the material would be found as $\mathrm{CaO}$. The literature mentions a tendency for outer layers of $\mathrm{CaO}$ to form during the annealing process 


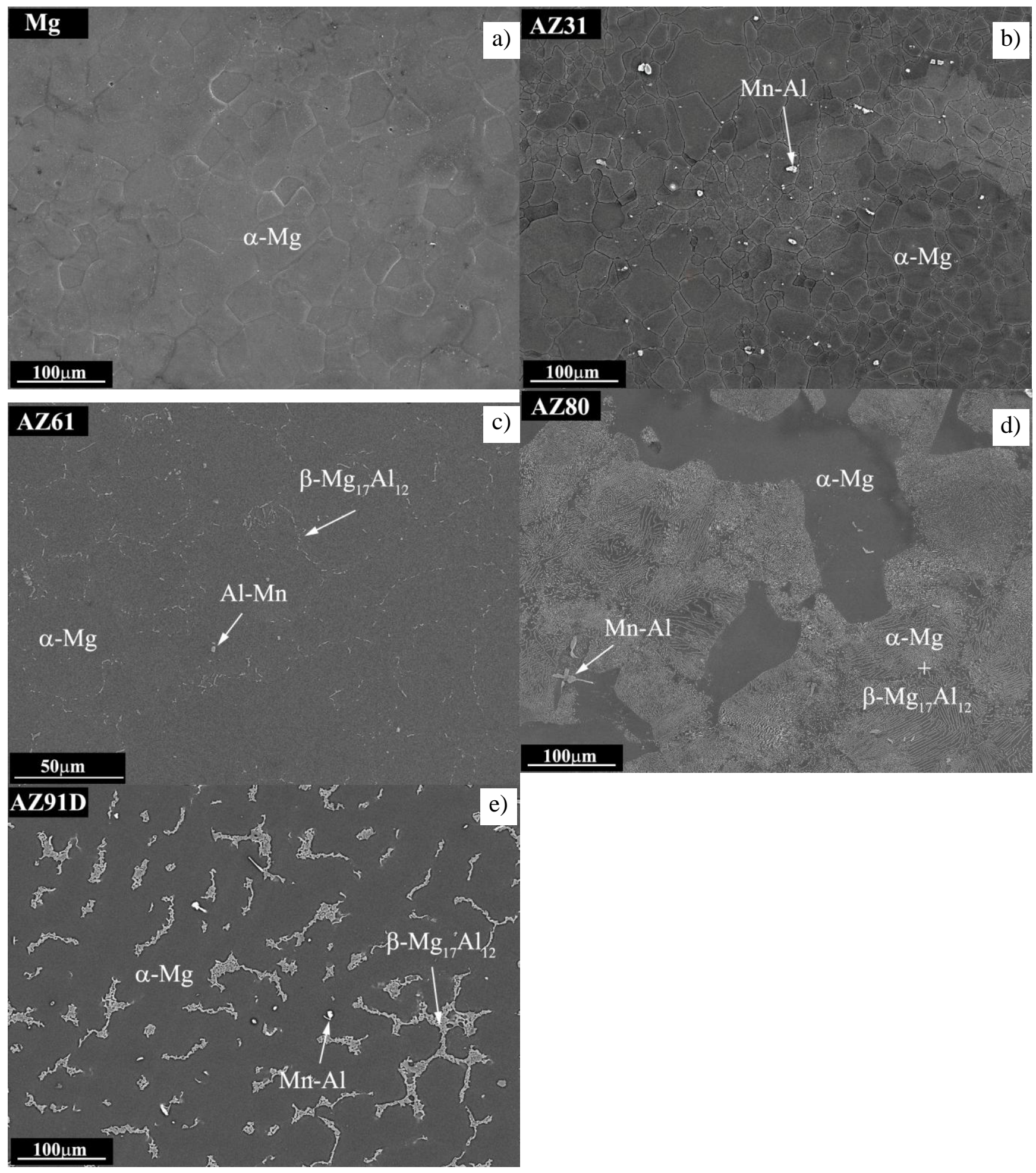

Fig. (3). Scanning electron micrographs (BSE mode) of (a) pure Mg, (b) AZ31 alloy, (c) AZ61 alloy, (d) AZ80 alloy and (e) AZ91D alloy.

of $\mathrm{MgO}(100)$ crystals that contain calcium as an impurity [47-49]. This enrichment is favoured because the relative Gibbs free energy per equivalent $\left(\Delta \mathrm{G}_{0} / \mathrm{n}\right)$ for the formation of calcium oxide is more positive than that for $\mathrm{MgO}$. The effect is similar to that observed in magnesium alloys with calcium additions as an alloying element [46, 50-52].
It is interesting to point out that the Ca content observed in the XPS analyses of the outer surface of $\mathrm{Mg}$ specimens tends to decrease rapidly as the argon ion bombardment time increases (Table $\mathbf{2}$ and Fig. 4). The significant calcium content in oxide form is probably limited to the outer surface of the material. This result is very similar to that obtained by Souda et al. [48], who, working with $\mathrm{MgO}$ crystals including 210 ppm bulk $\mathrm{Ca}$ impurities, found that $\mathrm{Ca}$ ions exist only in 
the outermost layer, and no $\mathrm{Ca}$ enrichment occurs in the deeper layers.

Table 2. Comparison of the $\mathrm{Ca} /(\mathrm{Ca}+\mathrm{Mg})$ Atomic Ratios Obtained in the Bulk of the Pure Mg and the Mg-Al Alloys by Chemical Analysis, and on their Outer Surface by XPS

\begin{tabular}{|c|c|c|}
\hline \multirow{2}{*}{ Material } & \multicolumn{2}{|c|}{ Ca/(Ca+Mg) Atomic Ratios } \\
\cline { 2 - 3 } & $\begin{array}{c}\text { Determined in the Bulk } \\
\text { by Chemical Analysis }\end{array}$ & $\begin{array}{c}\text { Determined on } \\
\text { the Surface by XPS }\end{array}$ \\
\hline \hline Pure Mg & $15,8.10^{-5}$ & 0.28 \\
\hline AZ31 & $8.8 \cdot 10^{-6}$ & 0.11 \\
\hline AZ61 & $8.5 \cdot 10^{-6}$ & 0.12 \\
\hline AZ80 & $8.6 \cdot 10^{-6}$ & 0.11 \\
\hline AZ91D & $9.4 .10^{-6}$ & 0.07 \\
\hline
\end{tabular}

\section{Ca $2 p$ peak}

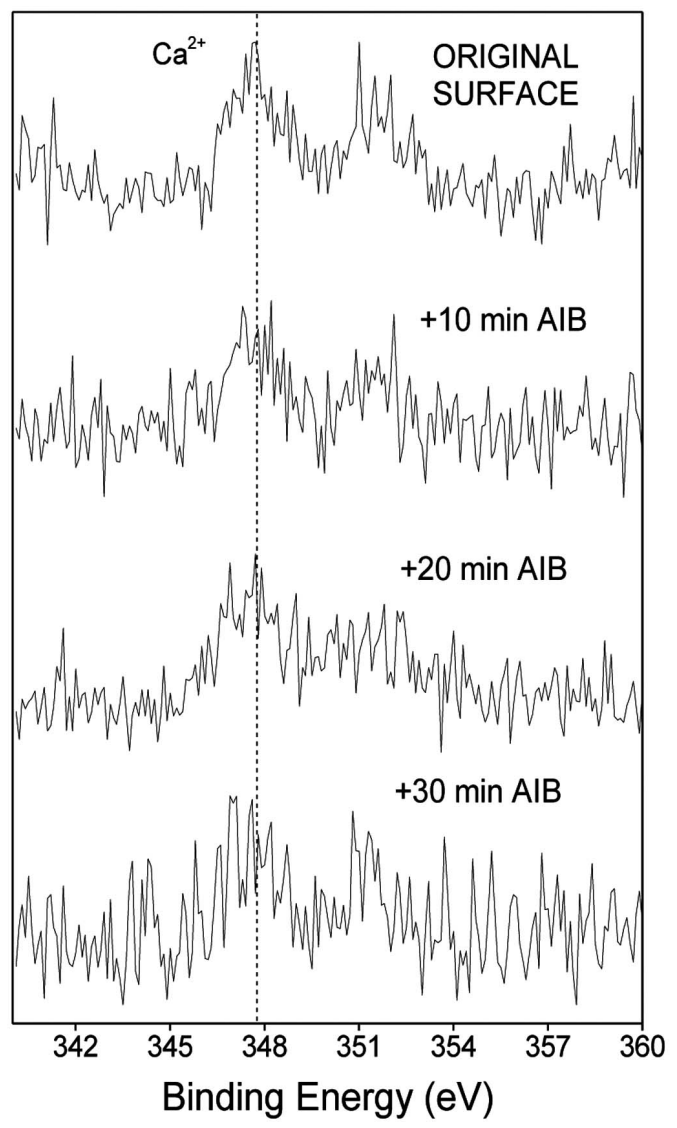

Fig. (4). Evolution of $\mathrm{Ca} 2 \mathrm{p}$ high resolution XPS spectra observed on the pure $\mathrm{Mg}$ surface with AIB time.

\subsubsection{EIS Measurements of the Natural Oxide Film Formed in Contact with the Air}

It was of interest to clarify whether the presence of a significant amount of calcium in oxide form on the outer surface of magnesium affords a protective effect to the metallic substrate. Gentle polishing of the pure $\mathrm{Mg}$ and AZ31 alloy surfaces was performed (thickness removed equivalent to $10 \mu \mathrm{m}$ determined from weight loss values) in order to eliminate Ca surface segregation. Fig. (5) compares the Nyquist diagrams obtained with the original magnesium and AZ31 alloy specimens (a) and after gentle polishing (b). Taking the original surface as the reference (Fig. 5a), polishing tends to reduce the size of the high and medium frequency arc in the Nyquist diagram (Fig. 5b), and thus the charge transfer resistance $\left(\mathrm{R}_{\mathrm{t}}\right)$ value associated with this arc. With regard to the importance of this effect, it is noted that the reduction is approximately by 4 times with pure $\mathrm{Mg}$ and by only 1.5 times with the AZ31 alloy. Bearing in mind that the thickness of the natural surface oxide film coating pure magnesium is very thin (Fig. 2f), and the logical absence of aluminium oxides on this surface, it may be speculated that the presence of a $\mathrm{CaO}$ layer on the magnesium surface is the cause of the considerably higher $R_{t}$ value. This would agree with the results of Jihua et al. [53] indicating that trace $\mathrm{Ca}$ addition was beneficial to corrosion resistance improvement of magnesium alloys.

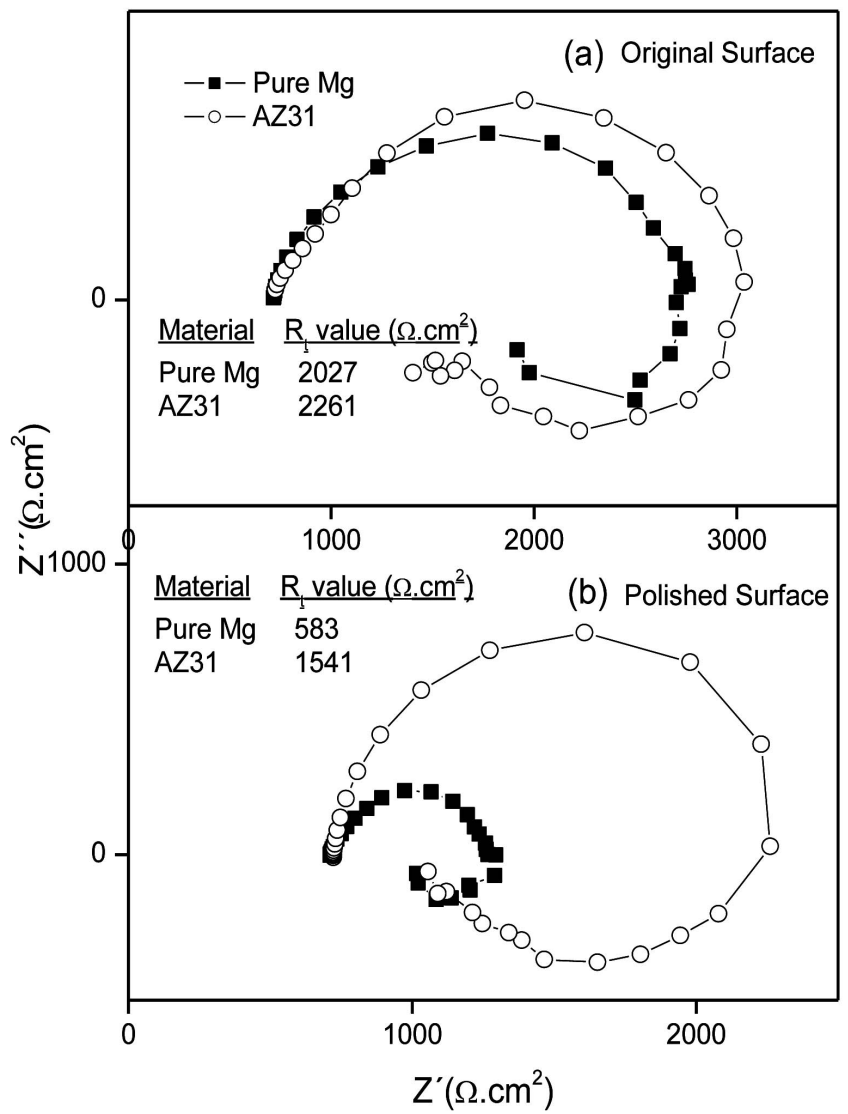

Fig. (5). Comparison of Nyquist diagrams obtained with the original $\mathrm{Mg}$ and AZ31 alloy specimens (a) and after gentle polishing (b).

3.2. Changes in Surface Chemistry and Corrosion Resistance During Exposure of the Material to a Humid Atmosphere

\subsubsection{XPS Characterisation of Thick Corrosion Film from the Humidity Condensation Test}

The methodology used was based on qualitative and quantitative XPS analysis of corrosion product films of different thickness. The corrosion film formed after 30 days 
of exposure of the AZ61 alloy to the humidity condensation test is analysed in detail. Similar analyses were performed with the other specimens and film exposure times.

3.2.1.1. Curve Fitting of XPS Spectra for the Main Corrosion Film Constituting Elements as a Function of Exposure Time

The active character of magnesium, its tendency to oxidise and its high oxygen affinity may explain why a thin film of highly hydrated magnesium hydroxide spontaneously forms on the corrosion product layers present on the surface of pure $\mathrm{Mg}$ and AZ31 and AZ61 alloys in contact with oxygen from the air [31]. This film prevents XPS from detecting aluminium (the main alloying element of these alloys). However, the film's effect is limited to a very superficial portion, since the removal of about $2 \mathrm{~nm}(10 \mathrm{~min}$ sputtering) is sufficient to detect the presence of aluminium. For this reason, the XPS spectra and the atomic percentages of elements and chemical species referred to below correspond to the surface obtained after 10 minutes of AIB.

Fig. (6a) shows the $\mathrm{C} 1 \mathrm{~s}$ high resolution XPS spectra of the AZ61 alloy surface after 30 days of exposure to the humid environment. The XPS spectra can be fitted with two components of a similar intensity. The first peak, located at $285.0 \mathrm{eV}$, is associated with the presence of residual $\mathrm{C}-\mathrm{C} / \mathrm{C}$ $\mathrm{H}$ groups (adventitious hydrocarbon contamination) [41] not completely removed by sputtering. At $290.5 \mathrm{eV}$ another component is observed which corresponds to carbonate $[1,42]$, suggesting the formation of a significant amount of magnesium carbonate on the surface of the exposed specimens (Fig. 6a).

The O1s high resolution spectra of alloy AZ61 after 30 days of exposure to the humid environment may be fitted with two components (Fig. 6b). The first is situated at approximately $531.0 \mathrm{eV}$ and is normally interpreted as oxygen in the form of magnesium oxide/aluminium oxide $[1,2,34]$. At $533 \cdot 2-533.4 \mathrm{eV}$ a more prominent peak is observed, which is attributed to the presence of $\mathrm{MgCO}_{3}$ and/or $\mathrm{Mg}(\mathrm{OH})_{2}$ [54].

The Mg2p XPS high resolution spectrum of alloy AZ61 after 30 days of humidity exposure is shown in Fig. (6c). The spectrum shows only one component which is associated with the presence of magnesium as $\mathrm{Mg}^{2+}$. Due to the strong overlap between the second bulk plasmon of the metallic $\mathrm{Mg} 2 \mathrm{p}$ peak and the A12p peak observed in our measurements, we have measured the A12s peak instead of the A12p peak [55]. The high resolution A12s spectrum for the AZ61 alloy after 30 days of humidity exposure revealed a single component at $120.5 \mathrm{eV}$ typical of aluminium in the form of $\mathrm{Al}_{2} \mathrm{O}_{3}$ (Fig. 6d) [56].

\subsubsection{Elementary Composition of the Corrosion Film as a} Function of Exposure Time

Table 3 shows the element composition of the surfaces of pure Mg, AZ31 and AZ61 alloys obtained by XPS before (0 days) and during the humidity test. The surface of the asreceived magnesium specimens (0 days) revealed a high carbon content, indicating that the cleaning process did not completely remove impurities from the outer surface, such as oils used during the storage and transportation of these materials. After one day in the humidity cabinet an important reduction in the carbon content and a relative increase in oxygen and magnesium were detected. These changes may be related with replacement of the initial metallic magnesium surface by a corrosion layer that is less enriched in $\mathrm{C}-\mathrm{C} / \mathrm{C}-\mathrm{H}$ groups. Extended exposure times did not produce significant changes in the atomic contents.

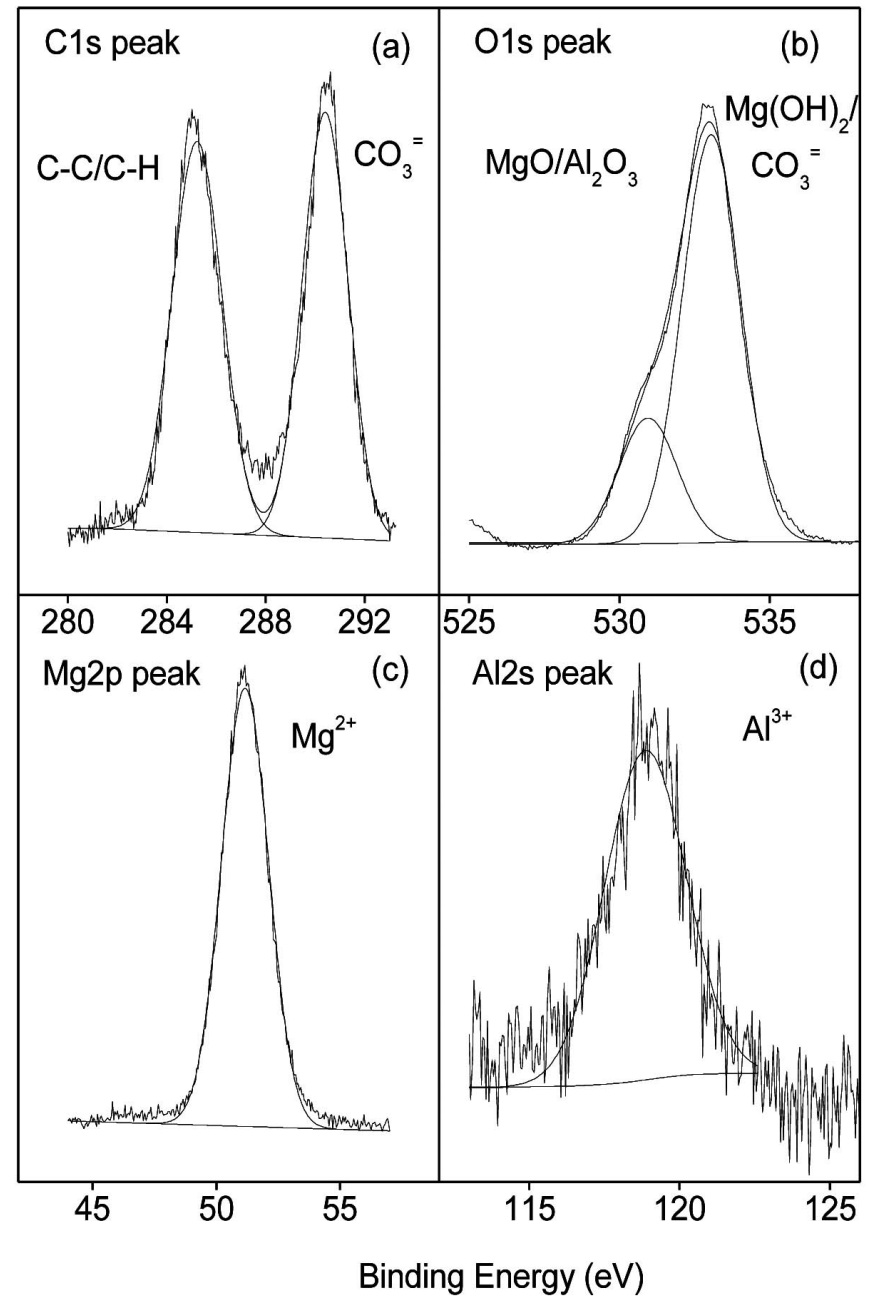

Fig. (6). C1s (a), O1s (b), Mg2p (c) and A12s (d) high resolution XPS spectra of the AZ61 alloy surface after exposure for 30 days to the humid environment.

Important differences are found in the $\mathrm{Al} /(\mathrm{Al}+\mathrm{Mg})$ atomic ratios calculated from the XPS data obtained on the unexposed specimen surfaces ( 0 days) and their evolution with exposure time. The $\mathrm{Al} /(\mathrm{Al}+\mathrm{Mg})$ atomic ratios observed on the unexposed surfaces of the AZ31 and AZ61 alloys (Table 3) are of the order of those mentioned in other papers $[2,18,24,57]$ for $\mathrm{Mg}$-Al alloys with aluminium contents of 2-10 wt.\% Al and suggest a moderate tendency towards aluminium segregation, whose concentration may increase at most by a factor of 2-3. In contrast with what was said above for calcium, the $\mathrm{Al} /(\mathrm{Al}+\mathrm{Mg})$ ratios obtained by XPS on the unexposed surfaces of AZ31 and AZ61 specimens (Table 3) is not proportional to the Al content in the bulk material (Table 1), and seems rather to indicate saturation of the outer surface of the specimens with aluminium, according to Table 3 around 15 wt.\%.

In alloy $\mathrm{AZ31}$ the $\mathrm{Al} /(\mathrm{Mg}+\mathrm{Al}) \times 100$ ratio decreases rapidly with humidity exposure until reaching a value, after 15 and 30 days of exposure, which is slightly higher (Table 
Tabla 3. Element Composition of the Corrosion Film as a Function of Exposure Time

\begin{tabular}{|c|c|c|c|c|c|c|c|c|}
\hline Sample & T(days) & $\% \mathrm{C}$ & $\% \mathbf{O}$ & $\% \mathrm{Mg}$ & $\% \mathbf{A l}$ & $\mathbf{A l} /(\mathbf{M g}+\mathbf{A l}) \times 100$ & $\mathrm{O} / \mathrm{Mg}$ & Most Probable Corrosion Compounds Obtained from the $\mathrm{O} / \mathrm{Mg}$ Ratio \\
\hline \multirow{3}{*}{ Pure $\mathrm{Mg}$} & 0 & 53 & 35 & 12 & 0 & 0 & 2.9 & \multirow{3}{*}{$\mathrm{CO}_{3} \mathrm{Mg}$} \\
\hline & 15 & 18 & 61 & 21 & 0 & 0 & 2.9 & \\
\hline & 30 & 21 & 62 & 17 & 0 & 0 & 3.6 & \\
\hline \multirow{3}{*}{ AZ31 } & 1 & 25 & 52 & 21 & 2 & 9 & 2.5 & \multirow{3}{*}{$\mathrm{CO}_{3} \mathrm{Mg}+\mathrm{MgO}$} \\
\hline & 15 & 22 & 55 & 22 & 1 & 4 & 2.5 & \\
\hline & 30 & 20 & 56 & 22 & 1 & 4 & 2.5 & \\
\hline AZ61 & 0 & 43 & 31 & 22 & 4 & 15 & 1.4 & $\mathrm{Mg}(\mathrm{OH})_{2}$ \\
\hline
\end{tabular}

3) than the aluminium content in the bulk metal composition $(3 \%)$ (Table 1). Thus it seems that if there is some aluminium enrichment, responsible for the higher corrosion resistance, this only occurs in a thin oxide layer, presumably near the metal/oxide interface but not in the corrosion layer. This observation is in agreement with Lindstrom et al. [8], who suggested that the significant improvement in corrosion resistance of $\mathrm{Mg}$-Al alloys may be attributed mainly to the alumina component of the inner layer becoming the dominant factor in determining the passivity of the surface.

Unlike the aforementioned behaviour for the AZ31 alloy, the $\mathrm{Al} /(\mathrm{Mg}+\mathrm{Al}) \times 100$ ratio detected by XPS in the corrosion products layer formed on the surface of the AZ61 alloy is similar to that observed in the initial unexposed film (approximately 15\%) (Table 3), greater than the aluminium content in the bulk metal composition (6\%) and does not seem to vary with exposure time. This data tends to suggest significant aluminium enrichment through the thick corrosion film formed on the AZ61 alloy after exposure to humid air.

Table 3 also shows the $\mathrm{O} / \mathrm{Mg}$ atomic ratios calculated from the XPS data obtained on the unexposed specimen surfaces, their evolution with exposure time by XPS, and the most probable corrosion products obtained from this ratio. With the pure $\mathrm{Mg}$ specimen an $\mathrm{O} / \mathrm{Mg}$ ratio of close to 3 is obtained, which tends to suggest the formation of $\mathrm{CO}_{3} \mathrm{Mg}$ as the main compound in the corrosion product layer. The $\mathrm{O} / \mathrm{Mg}$ ratio in the AZ31 alloy (Table 3 ) reaches a value of 2.5 after 1 day of exposure and remains around this value after 30 days of exposure. The lowering of this value compared with the value of 3.0 corresponding to $\mathrm{CO}_{3} \mathrm{Mg}$ could be directly related with the presence of $\mathrm{MgO}$ in the corrosion products layer formed on the AZ31 alloy. The value of the $\mathrm{O} / \mathrm{Mg}$ ratio obtained in the corrosion products layer formed on the AZ61 alloy (around 2.0) is lower than on the AZ31 alloy and the pure $\mathrm{Mg}$ (Table 3 ). The $\mathrm{O} / \mathrm{Mg}$ ratios of $\approx 2.0$ reflect the existence of $\mathrm{Mg}(\mathrm{OH})_{2}$ as the major component of the corrosion products layer formed on the AZ61 alloy, probably related with the presence of a high Al content.
3.2.1.3. Chemical Composition of the Corrosion Film as a Function of Exposure Time

Table 4 compares the atomic percentages of $\mathrm{C}---\mathrm{C} / \mathrm{C}---\mathrm{H}$ and $\mathrm{CO}_{3}{ }^{=}$groups obtained from the areas of the different components used in the fitting of the $\mathrm{C} 1 \mathrm{~s}$ spectrum (Fig. 6a), the atomic percentages of $\mathrm{MgO} / \mathrm{Al}_{2} \mathrm{O}_{3}$ and $\mathrm{CO}_{3}{ }^{=} / \mathrm{Mg}(\mathrm{OH})_{2}$ groups obtained from the areas of the different components used in the fitting of the O1s spectrum (Fig. 6b), and the atomic percentage of $\mathrm{C}$ and $\mathrm{O}$ observed by XPS on the surfaces of the pure $\mathrm{Mg}, \mathrm{AZ31}$ and AZ61 alloys after exposure to the humidity condensation test (Table $\mathbf{3}$ ). As the Mg2p spectra (Fig. 6c) and A12s spectra (Fig. 6d) are fitted with a single component, the atomic percentage of $\mathrm{Mg}$ and Al shown in Table 3 could be mainly attributed to the presence of $\mathrm{Mg}$ as $\mathrm{Mg}^{2+}$ and $\mathrm{Al}$ as $\mathrm{Al}^{3+}$.

After only one day of exposure the XPS analysis of the pure $\mathrm{Mg}$ and the AZ31 and AZ61 alloy surfaces detects the presence of considerable percentages of carbonates (between 6 and 9\%) (Table 4). In a carbon dioxide $\left(\mathrm{CO}_{2}\right)$ containing atmosphere, when a thin electrolyte layer is presented on the metal surface, $\mathrm{CO}_{2}$ readily diffuses to the film surface and tends to form magnesium carbonate.

For pure $\mathrm{Mg}$, the detected $\mathrm{CO}_{3}{ }^{=}$atomic percentage obtained from the carbon and oxygen elements increases, whereas the amount of $\mathrm{MgO}$ obtained from the oxygen continuously decreases during the test and almost disappears after 30 days of exposure to the humid environment. (Table 4). This result suggests that the magnesium oxide present on the pure $\mathrm{Mg}$ surface does not prevent appreciable attack of the material and readily reacts with $\mathrm{CO}_{2}$ from the air to form magnesium carbonate.

Different behaviour was revealed for the surface of the AZ31 alloy, where the amount of $\mathrm{MgO}$ remained practically constant between 15 and 30 days (Table 4). Regarding carbonate content, while it slightly increased for pure $\mathrm{Mg}$ it remained constant for the AZ31 alloy. The scarce variation of these values suggests stabilisation of the surface composition due to the presence of aluminium. 
Table 4. Chemical Species Composition of the Corrosion Films as a Function of Exposure Time

\begin{tabular}{|c|c|c|c|c|c|}
\hline \multicolumn{3}{|c|}{ Material } & \multicolumn{3}{|c|}{ Atomic Percent (Exposure Time in Days) } \\
\hline & Element & Chemical Species & 1 & 15 & 30 \\
\hline \multirow{4}{*}{ Pure Mg } & \multirow{2}{*}{ Carbon } & $\mathrm{C}-\mathrm{C} / \mathrm{C}-\mathrm{H}$ & 15 & 8 & 9 \\
\hline & & $\mathrm{CO}_{3}=$ & 9 & 10 & 12 \\
\hline & \multirow{2}{*}{ Oxygen } & $\mathrm{MgO} / \mathrm{Al}_{2} \mathrm{O}_{3}$ & 19 & 16 & 6 \\
\hline & & $\mathrm{CO}_{3}=/ \mathrm{Mg}(\mathrm{OH})_{2}$ & 37 & 45 & 56 \\
\hline \multirow{4}{*}{ AZ31 alloy } & \multirow{2}{*}{ Carbon } & $\mathrm{C}-\mathrm{C} / \mathrm{C}-\mathrm{H}$ & 19 & 14 & 8 \\
\hline & & $\mathrm{CO}_{3}{ }^{=}$ & 6 & 8 & 8 \\
\hline & \multirow{2}{*}{ Oxygen } & $\mathrm{MgO} / \mathrm{Al}_{2} \mathrm{O}_{3}$ & 27 & 18 & 22 \\
\hline & & $\mathrm{CO}_{3}=/ \mathrm{Mg}(\mathrm{OH})_{2}$ & 25 & 37 & 39 \\
\hline \multirow{4}{*}{ AZ61 } & \multirow{2}{*}{ Carbon } & $\mathrm{C}-\mathrm{C} / \mathrm{C}-\mathrm{H}$ & 23 & 7 & 8 \\
\hline & & $\mathrm{CO}_{3}{ }^{=}$ & 6 & 6 & 8 \\
\hline & \multirow{2}{*}{ Oxygen } & $\mathrm{MgO} / \mathrm{Al}_{2} \mathrm{O}_{3}$ & 25 & 20 & 13 \\
\hline & & $\mathrm{CO}_{3}{ }^{=} / \mathrm{Mg}(\mathrm{OH})_{2}$ & 18 & 36 & 43 \\
\hline
\end{tabular}

Unlike the absence of significant changes observed by XPS on the AZ31 alloy, attention is drawn to the constant decline in the $\mathrm{MgO}$ content and the rise in the $\mathrm{CO}_{3}{ }^{=} / \mathrm{Mg}(\mathrm{OH})_{2}$ content observed on the AZ61 alloy surface as the exposure time increases (Table 4). As has been pointed out above, the $\mathrm{CO}_{3}{ }^{2} / \mathrm{Mg}(\mathrm{OH})_{2}$ species content in the corrosion product layer on alloy AZ61 is due mainly to the presence of $\mathrm{Mg}(\mathrm{OH})_{2}$. Thus, the important variation in the chemical composition observed after 30 days of exposure seems to be linked to the formation of $\mathrm{Mg}(\mathrm{OH})_{2}$ from the $\mathrm{MgO}$ present on the initial AZ61 alloy surface.

\subsubsection{Electrochemical Impedance Spectra Analysis of the Thick Corrosion Products Layer Formed After Different Exposure Times}

3.2.2.1. Initial Stage. Removal of Natural Oxide Film and Characteristics of the Layer that Replaces it

Fig. (7) compares the Nyquist diagrams obtained with pure magnesium (a), AZ31 (b) and AZ61 (c) alloys in different surface conditions. These conditions were the original surface after exposure to the laboratory atmosphere for a long time (several months), the same surface after exposure to the humidity condensation test for one day, and finally the surface simply polished. The diagrams present a single arc with an inductive tail at the lower frequencies. Fig. (7) also shows the change in charge transfer resistance values, $\mathrm{R}_{\mathrm{t}}$, which are deduced from the high and medium frequency arc of the Nyquist plots. The charge transfer resistance value $R_{t}$ decreases from $2.26 \mathrm{k} \Omega . \mathrm{cm}^{2}$ in the unexposed AZ31 alloy to $1.25 \mathrm{k} \Omega . \mathrm{cm}^{2}$ for the specimen after 1 day of exposure (Fig. 7b), and from $8.8 \mathrm{k} \Omega . \mathrm{cm}^{2}$ on the unexposed AZ61 alloy to $4.67 \mathrm{k} \Omega . \mathrm{cm}^{2}$ (Fig. 7c). The $\mathrm{R}_{\mathrm{t}}$ values obtained with the AZ31 and AZ61 alloys after 1 day of exposure to the humidity condensation test are similar to those obtained on the non-exposed polished samples (Figs. $\mathbf{7 b}, \mathbf{c})$. This data suggests the rapid removal, by the rinsing effect of condensed water, of a very high percentage of the initial air-formed film composed of $\mathrm{MgO}$ and $\mathrm{CaO}$.
3.3. Second Stage. Effect of Aluminium on the Formation of Passivating and Protective Layers as a Result of the Exposure Process

No great differences have been seen in the general shape of the impedance diagrams corresponding to pure $\mathrm{Mg}$ and AZ61 alloy with exposure time to the humidity condensation test. However, important differences were observed in the charge transfer resistance values calculated from these diagrams (Fig. 8a, b). Taking as reference the pure $\mathrm{Mg}$ and AZ61 alloy surfaces exposed for 1 day, the exposure time tends to increase the size of the high and medium frequency arc in the Nyquist diagram, and thus the charge transfer resistance value $\left(R_{t}\right)$ associated with this arc (Fig. 8a, b). With regard to the importance of this effect, it may be noted that after 30 days of exposure to the humidity condensation test the $R_{t}$ value has increased by around 5 times with the pure $\mathrm{Mg}$ (Fig. 8a) and around 8 times with the AZ61 alloy (Fig. 8b). As for the protective efficiency of the corrosion layer that is formed, it should be noted that it took 30 days of exposure for the $\mathrm{R}_{\mathrm{t}}$ values observed with the pure $\mathrm{Mg}$ (Fig. 8a), to reach a similar value to that observed with the unexposed AZ61 alloy $\left(\sim 8.8 \mathrm{k} \Omega . \mathrm{cm}^{2}\right.$, Fig 7c).

As with the $\mathrm{R}_{\mathrm{t}}$ values, the magnesium carbonate content observed by XPS in the surface film of pure $\mathrm{Mg}$ rises constantly over the 30 days of exposure (Table 4). Therefore, the increase observed in the $\mathrm{R}_{\mathrm{t}}$ values of pure $\mathrm{Mg}$ must be related with the increase in the magnesium carbonate content in the corrosion products layer formed in humidity exposure, which would improve the anticorrosive resistance of pure $\mathrm{Mg}$.

The $R_{t}$ values of the AZ61 alloy rise from a value of 4.67 $\mathrm{k} \Omega . \mathrm{cm}^{2}$, measured after 1 day of exposure, to a value of $43.50 \mathrm{k} \Omega . \mathrm{cm}^{2}$ after 30 days of exposure (Fig. 8b). As has been noted above, the XPS analyses obtained with this alloy indicate a highly significant $\mathrm{Al}$ content and the constant formation of $\mathrm{Mg}(\mathrm{OH})_{2}$ in the corrosion layer on AZ61 up to 30 days of exposure (Table 3). This data tends to suggest that corrosion product layers constituted by mixtures of alumi- 

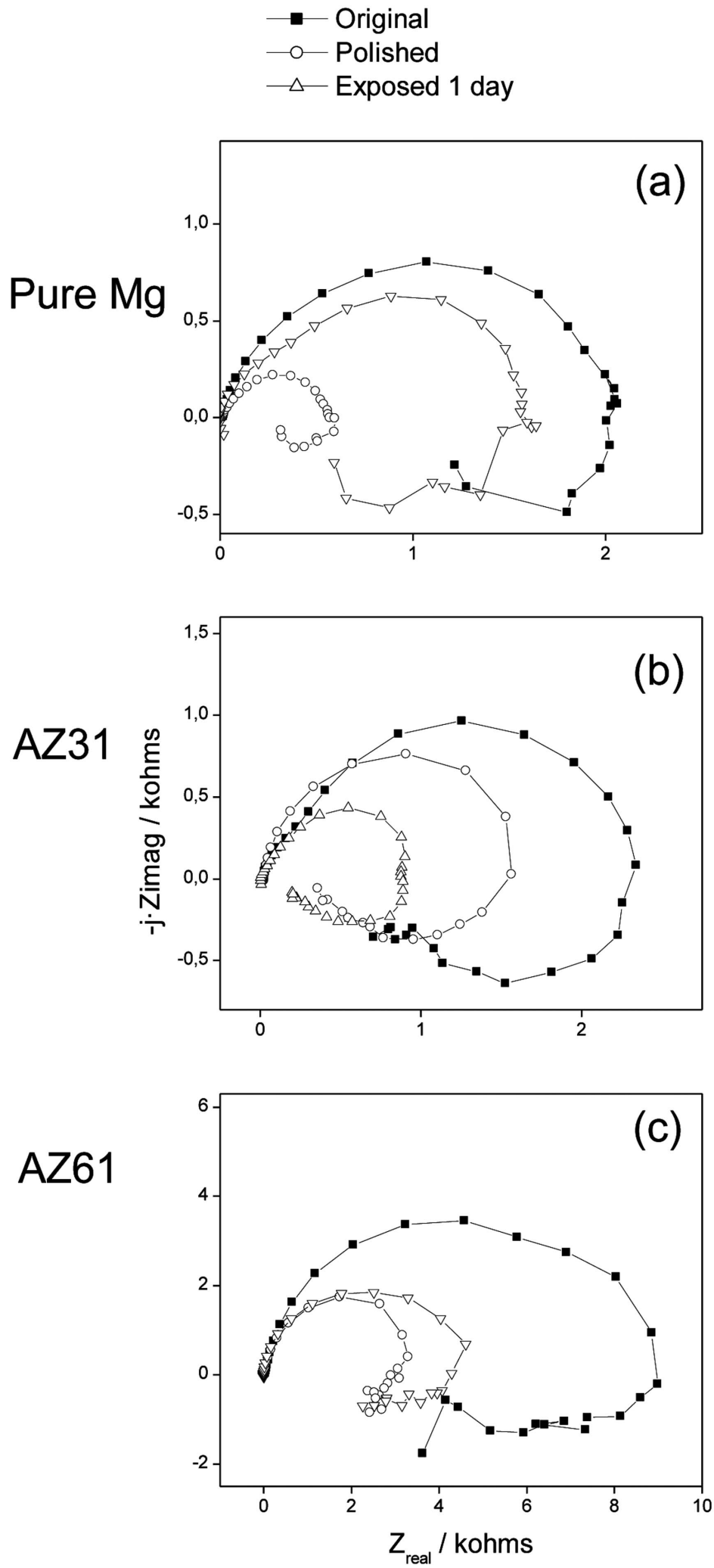

Material $\quad \mathrm{R}_{1}$ value $\left(\mathrm{k} \Omega \cdot \mathrm{cm}^{2}\right)$

Original 2.02

Polished 0.58

1 day of 18.99

exposure
Material $\underline{\mathrm{R}}$ value $\left(\mathrm{k} \Omega . \mathrm{cm}^{\underline{2}}\right)$

Original 2.26

Polished 1.54

1day of 1.25

exposure

\author{
Material $\quad \underline{R}$ value $\left(\mathrm{k} \Omega . \mathrm{cm}^{2}\right)$ \\ Original 8.80 \\ Polished 3.25 \\ 1day of 4.67 \\ exposure
}

Fig. (7). Nyquist diagrams obtained with pure Mg (a), AZ31 (b) and AZ61 (c) specimens in different surface conditions.

nium oxide and $\mathrm{Mg}(\mathrm{OH})_{2}$ very significantly increase the corrosion resistance of the AZ61 alloy.

Unlike the diagrams observed for pure $\mathrm{Mg}$ and the AZ61 alloy (Fig. 8a, b), the impedance diagram obtained with the exposed AZ31 alloy tends to present two semicircles after 30 days (Fig. 8c). A semicircle related with the protective character of the corrosion product layer is represented at high frequencies, while at low frequencies the Warburg 
- 1 day of exposure

$-0-15$ days of exposure

$\rightarrow-30$ days of exposure
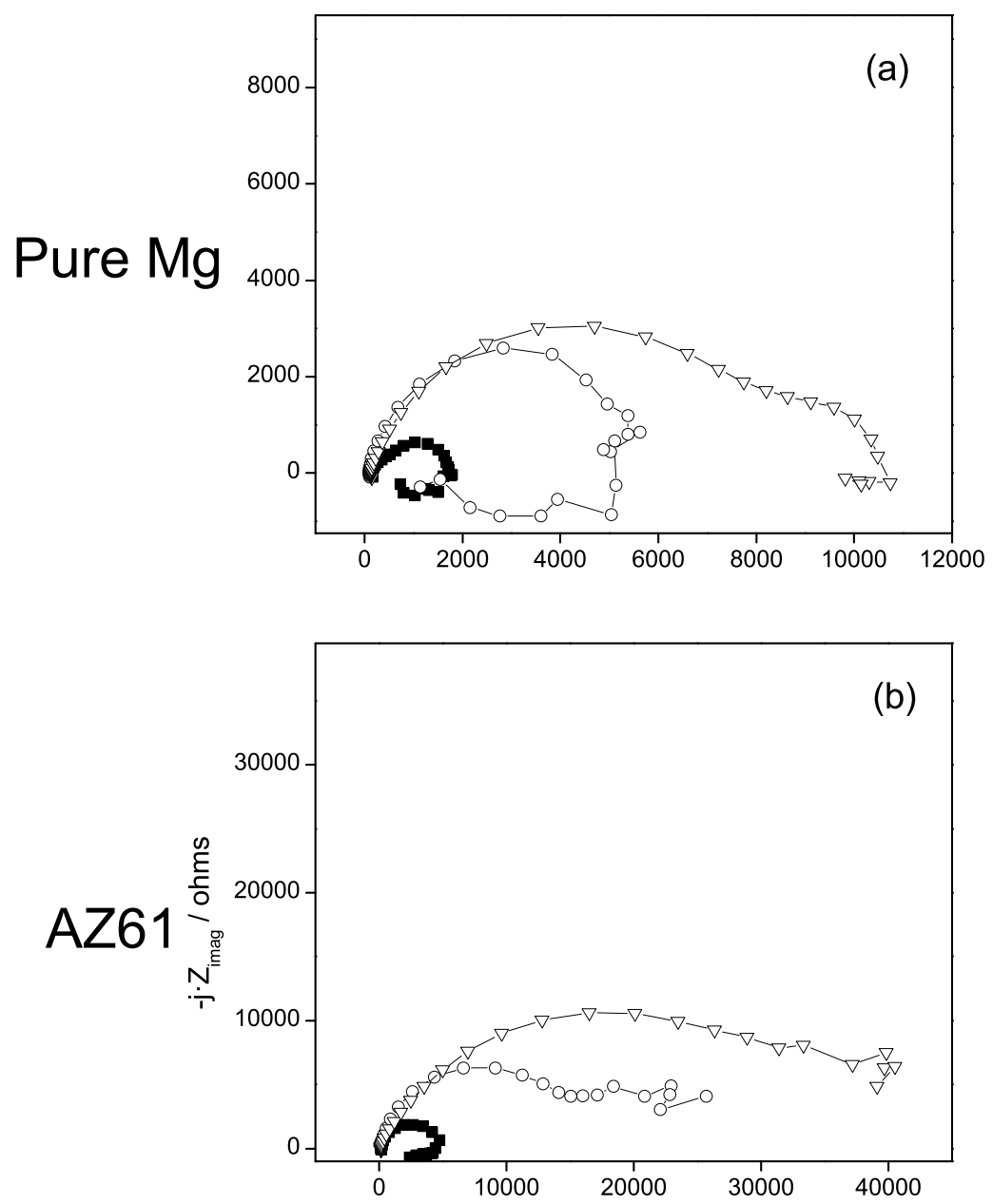

\begin{tabular}{|c|c|}
\hline Material & $\underline{R}$ value $\left(\Omega \cdot \mathrm{cm}^{\underline{2}}\right)$ \\
\hline 1 day & 1900 \\
\hline 15 days & 5700 \\
\hline $\begin{array}{l}30 \text { day of } \\
\text { exposure }\end{array}$ & 9800 \\
\hline
\end{tabular}

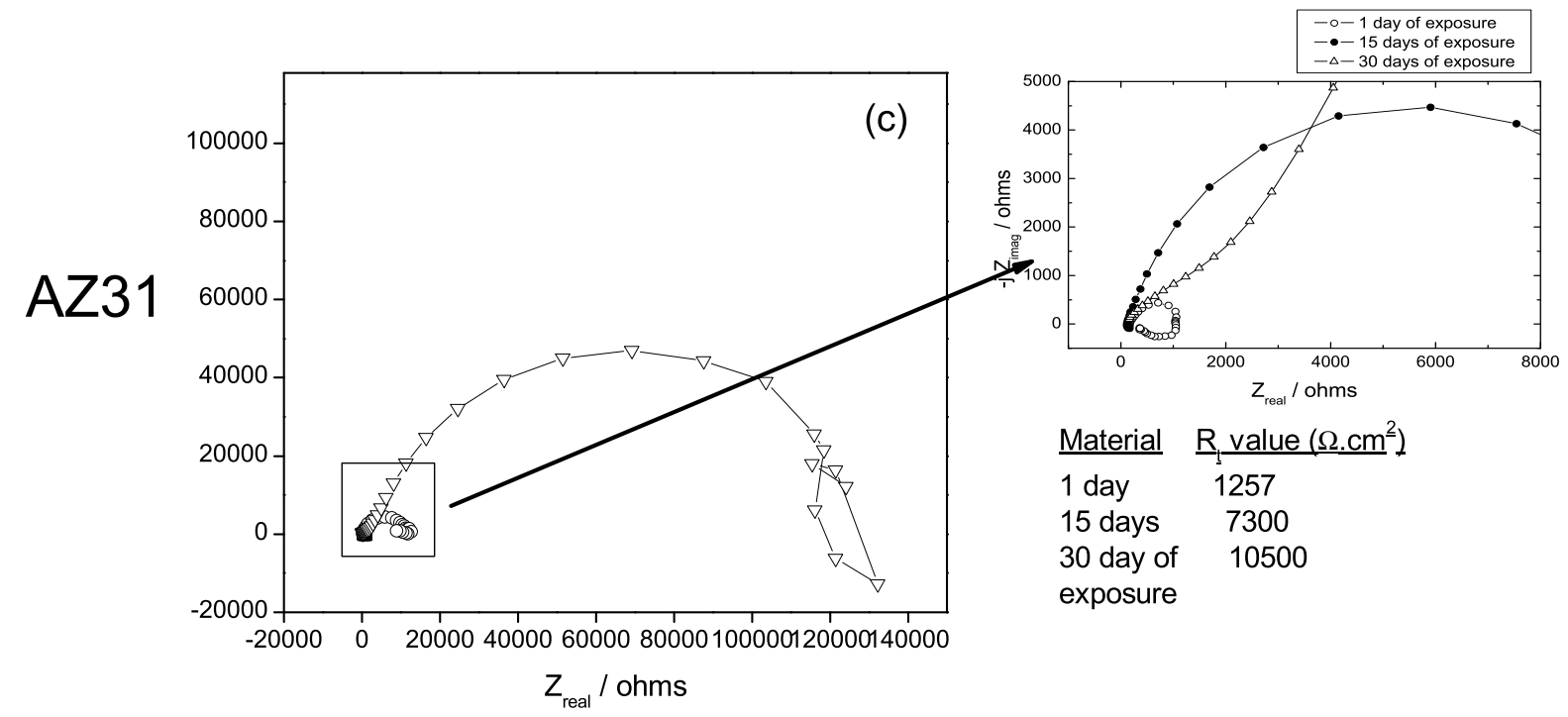

Fig. (8). Evolution of Nyquist diagrams obtained with pure Mg (a), AZ61 (b) and AZ31 (c) specimens after different exposure times. 
impedance appears in the form of an arc or diffusion tail. In the impedance diagram for the AZ31 alloy after 30 days of exposure, the appearance at low frequencies of a poorlydefined second arc or tail of a much larger diameter than that appearing at high frequencies may be attributed to the influence on the frequency response of the diffusion process through the corrosion products layer of finite thickness. Unlike pure $\mathrm{Mg}$, the $\mathrm{MgO}$ and magnesium carbonate contents observed by XPS on the AZ31 alloy surface after 15 days of exposure does not show significant variations compared with those seen after 30 days of exposure (Table 4). The scarce variation of these values shows that the presence of the $\mathrm{MgO}$ layer on the AZ31 alloy prevents the formation of magnesium carbonate. On the other hand, and in contrast with the $\mathrm{AZ61}$ alloy, the $\mathrm{Al} /(\mathrm{Mg}+\mathrm{Al}) \times 100$ ratio for the surface film of the AZ31 alloy after 15-30 days (Table 3 ) is slightly higher than the aluminium content in the bulk metal composition (Table 1). Therefore, according to the XPS results there is no aluminium enrichment on the outer surface of the corrosion products $(\sim 20 \AA \hat{)})$. This data suggests that the presence of the mixture of aluminium and magnesium oxides in a thin oxide layer, presumably near the metal/oxide interface and below the corrosion layer formed by $\mathrm{CO}_{3} \mathrm{Mg}$, increases the corrosion resistance of the AZ31 alloy, acting as a barrier that impedes the diffusion of aggressive species to the metallic substrate.

\section{SUMMARY}

This paper has summarised some of our work using XPS in corrosion research of magnesium and $\mathrm{Mg}-\mathrm{Al}$ alloys. With respect to the thin passivating film that forms spontaneously on the surface of magnesium and its alloys (thickness between 3 and $7 \mathrm{~nm}$ ), a technique like XPS provides information on the oxide film chemical composition and its thickness, film alloying element content and the presence of impurities. The composition of the thick corrosion products layer that forms subsequently during humidity exposure can also be determined. In general, the information obtained by the XPS technique leads to a better understanding of corrosion phenomena and mechanisms.

\section{ACKNOWLEDGEMENTS}

We wish to express our gratitude to Prof. S. Feliu for several claifying and stimulating discussions during the course of this work. Also, the authors gratefully acknowledge the financial support for this work from the Ministry of Science and Innovation of Spain (MAT200604486 project and MAT 2009-13530).

\section{REFERENCES}

[1] Fournier V, Marcus P, Olefjord I. Oxidation of magnesium. Surf Interface Anal 2002; 34: 494-7.

[2] Kim J, Wong KC, Wong PC, Kunlich SA, Metson JB, Mitchell KAR. Characterization of AZ91 magnesium alloy and organosilane adsorption on its surface. Appl Surf Sci 2007; 253: 4197-207.

[3] Fotea C, Callaway J, Alexander MR. Characterisation of the surface chemistry of magnesium exposed to the ambient atmosphere. Surf Interface Anal 2007; 38: 1363-71.

[4] Mc Intyre NS, Chen C. Role of impurities on Mg surfaces under ambient exposure conditions. Corrosion Sci 1998; 40: 1697-709.

[5] Nordlien JH, Ono S, Masuko N, Nisancioglu K. A TEM investigation of naturally formed oxide films on pure magnesium. Corrosion Sci 1997; 39: 1397-414.
[6] Splinter SJ, McIntyre NS. The initial interaction of water vapour with $\mathrm{MgAl}$ alloy surfaces at room temperatures. Surf Sci 1994; 314: 157-71.

[7] Lindstrom R, Svenson JE, Johansson LG. The influence of carbon dioxide on the atmospheric corrosion of some magnesium alloys in the presence of NaCl. J Electrochem Soc 2002; 149: B103-7.

[8] Lindstrom R, Johansson LG, Thompson GE, Skeldon P, Svensson JE. Corrosion of magnesium in humid air. Corrosion Sci 2004; 46: 1141-58.

[9] Johnsson M, Persson D, Gubner R. The initial steps of atmospheric corrosion on magnesium alloy AZ91D. J Electrochem Soc 2007; 154: C684-91.

[10] Johnsson M, Persson D, Thierry D. Corrosion product formation during $\mathrm{NaCl}$ induced atmospheric corrosion of magnesium alloy AZ91D. Corrosion Sci 2007; 49: 1540-58.

[11] Nordlien JH, Ono S, Masuko N, Nisancioglu K. Morphology and structure of oxide films formed on magnesium by exposure to air and water. J Electrochem Soc 1995; 142: 3320-2.

[12] Baril G, Pebere N. Corrosion of pure magnesium in aereated and deaerated sodium sulphate solutions. Corrosion Sci 2001; 43: 47184.

[13] Ballerini G, Bardi U, Bignucolo R, Ceraolo G. About some corrosion mechanisms of AZ91D magnesium alloys. Corrosion Sci 2005; 47: 2173-84.

[14] Song G, Atrens A, Wu X, Zhang B. Corrosion behaviour of AZ21, AZ501 and AZ91 in Sodium Chloride. Corrosion Sci 1998; 40: 1769-91.

[15] Pardo A, Merino MC, Coy AE, Arrabal R, Viejo F, Matykina E. Corrosion behaviour of magnesium/aluminium alloys in 3,5 wt $\%$ $\mathrm{NaCl}$. Corrosion Sci 2008; 50: 823-34.

[16] Pardo A, Merino MC, Coy AE, Viejo F, Arrabal R, Feliu Jr S. Influence of microstructure and composition on the corrosion behaviour of $\mathrm{Mg} / \mathrm{Al}$ alloys in chloride media. Electrochim Acta 2008; 53: 7890-902.

[17] Song G, Atrens A, Stjohn D, Naim J, Li Y. The electrochemical corrosion of pure magnesium in $\mathrm{NaCl}$. Corrosion Sci 1997; 39: 855-75.

[18] Nordlien JH, Nisancioglu K, Ono S, Masuko N. Morphology and structure of oxide films on $\mathrm{MgAl}$ alloys by exposure to air and water. J. Electrochem Soc 1996; 143: 2564-72.

[19] Nordlien JH, Nisancioglu K, Ono S, Masuko N. Morphology and structure of water-formed oxides on ternary MgAl alloys. J. Electrochem Soc 1997; 144: 461-6.

[20] Lunder O, Lein JE, Aune TK, Nisancioglu K. Role of Mg17Al12 phase in the corrosion of Mg alloy AZ91. Corrosion 1989; 45: 7418.

[21] Song GL, Atrens A, Dargusch M. Influence of microstructure on the corrosion of diecast AZ91D. Corrosion Sci 1998; 41: 249-73.

[22] Lindstrom R, Johansson LG, Svensson JE. The influence of $\mathrm{NaCl}$ and $\mathrm{CO} 2$ on the atmospheric corrosion of magnesium alloy AZ91. Mater Corros 2003; 54: 587-94.

[23] Ambat R, Aung NN, Zhou W. Evaluation of microstructural effects on corrosion behaviour of AZ91D magnesium alloy. Corrosion Sci 2000; 42: 1433-55.

[24] Mathieu S, Rapin C, Steinmetz J, Steinmetz P. A corrosion study of the main constituent phases of AZ91 magnesium alloy. Corrosion Sci 2003; 45: 2741-55.

[25] Shi Z, Song GL, Atrens A. Influence of the $\beta$ phase on the corrosion performance of anodized coating on magnesiumaluminium. Corrosion Sci 2005; 47: 2760-77.

[26] Song GL, Atrens A. Corrosion mechanisms of magnesium alloys. Adv Eng Mater 1999; 1: 11-33.

[27] Song GL, Atrens A. Recent insights into the mechanism of magnesium corrosion and research suggestions. Adv Eng Mater 2007; 9: 177-83.

[28] Makar GL, Kruger J. Corrosion studies of rapidly solified magnesium alloys. J Electrochem Soc 1990; 137: 414-21.

[29] Song GL, Atrens A. Understanding magnesium corrosion. A framework for improved alloy performance. Adv Eng Mater 2003; 5: 837-58.

[30] Feliu S Jr, Pardo A, Merino MC, Coy AE, Viejo F, Arrabal R. Correlation between the surface chemistry and the atmospheric corrosion of AZ31, AZ80 and AZ91D magnesium alloys. Appl Surf Sci 2009; 255: 4102-8. 
[31] Feliu Jr S, Merino MC, Arrabal R, Coy AE, Matykina E. XPS study of the effect of aluminium on the atmospheric corrosion of the AZ31 magnesium alloy. Surf Interface Anal 2009; 41:143-50.

[32] Graham MJ. The application of surface techniques in understanding corrosion phenomena and mechanisms. Corrosion Sci 1995; 37: 1377-97.

[33] Wagner CD, Davis LE, Zeller MV, Taylor JA, Raymond RH, Gale L. Empirical atomic sensitivity factors for quantitative analysis by electron spectroscopy for chemical analysis. Surf Interface Anal 1981; 3: 211-25

[34] Yao HB, Li Y, Wee ATS. XPS investigation of the oxidation/corrosion of melt-spun Mg. Appl Surf Sci 2000; 158: $112-9$.

[35] Strohmeier BR. ESCA method for determining the oxide thickness on aluminium alloys. Surf Interface Anal 1990; 15: 51-6.

[36] Chen C, Splinter SJ, Do T, McIntyre NS. Measurement of oxide film growth on $\mathrm{Mg}$ and $\mathrm{Al}$ surfaces over extended periods using XPS. Surf Sci 1997; 382: L652-7.

[37] Tanuma S, Powell CJ, Penn DR. Calculations of electron inelastic mean free paths. II. Data for 27 elements over the $50-2000 \mathrm{eV}$ range. Surf Interface Anal 1991; 17: 911-26.

[38] Akkerman A, Boutboul T, Breskin A, Chechik R, Gibrekhterman A, Lifshitz Y. Inelastic electron interactions in the energy range 50 $\mathrm{eV}$ to $10 \mathrm{keV}$ in insulators: Alkali halides and metal oxides. Phys Stat Sol (b) 1996; 198: 769-84.

[39] Powell CJ, Jablonski A. NIST electron inelastic-mean-free-path database, SRD 71. Gaithersburg: Department of Commerce (US), National Institute of Standards and Technology 2000.

[40] Do T, Splinter SJ, Chen C, McIntyre NS. The oxidation kinetics of Mg and Al surfaces studied by AES and XPS. Surf Sci 1997; 387: 192-8.

[41] Feliu S Jr, Perez- Revenga ML. Effect of the presence of alloying elements in interstitial-free and low-carbon steels on their surface composition after annealing in reducing atmospheres (dew point=$30^{\circ} \mathrm{C}$ ). Met Mater Trans A 2004; 35A: 2039-50.

[42] Asami K, Ono S. Quantitative X-ray photoelectron spectroscopy characterization of magnesium oxidized in air. J Electrochem Soc 2000; 147: 1408-13.

[43] Feliu S Jr, Bartolomé MJ. Influence of alloying elements and etching treatment on the passivating films formed on aluminium alloys. Surf Interface Anal 2007; 39: 304-16.
[44] Czerwinski F. The oxidation behaviour of an AZ91D magnesium alloy at high temperatures. Acta Mater 2000; 50: 2639-54.

[45] Feliu S Jr, Barranco V. XPS study of the surface chemistry of conventional hot-dip galvanised pure $\mathrm{Zn}$, galvanneal and $\mathrm{Zn}-\mathrm{Al}$ alloy coatings on steel. Acta Mater 2003; 51: 5413-24.

[46] Lee DB, Song L, Kim YJ. Effect of $\mathrm{Ca}$ and $\mathrm{CaO}$ on the high temperature oxidation of AZ91D Mg alloys. Mater Trans 2008; 49: 1084-8.

[47] Ota H, Sakai K, Aoki R, Ikeyima N, Hara S. Superstructure observation on $\mathrm{MgO}(100)$ surface. Surf Sci 1996; 357-358: 150-4.

[48] Souda R, Hwang Y, Aizawa T, Hayami W, Oyoshi K. Ca segregation at the $\mathrm{MgO}(001)$ surface studied by ion scattering spectroscopy. Surf Sci 1997; 387: 136-41.

[49] McCune RC, Wynblatt P. Calcium segregation to a magnesium oxide (100) surface. J Am Ceram Soc 1983; 66: 111-7.

[50] You BS, Park WW, Chung IS. Effect of calcium additions on the oxidation behaviour in magnesium alloys. Scr Mater 2000; 42: 1089-94.

[51] Masaki K, Ochi Y, Kakiuchi T, et al. High cycle fatigue property of extruded non-combustible $\mathrm{Mg}$ alloy AMCa602. Mater Trans 2008; 49: 1148-56.

[52] Ha SH, Lee JK, Kim SK. Effect of $\mathrm{CaO}$ on oxidation resistance and microstructure of pure Mg. Mater Trans 2008; 49: 1081-3.

[53] Jihua C, Zhenhua C, Hongge Y, Fuquan Z, Yingliang C. Effects of $\mathrm{Sn}$ and $\mathrm{Ca}$ additions on microstructure, mechanical properties, and corrosion resistance of the as-cast $\mathrm{Mg}-\mathrm{Zn}-\mathrm{Al}$ based alloy. Mater Corrosion 2008; 59: 934-41.

[54] Hosking NC, Ström MA, Shipway PH, Rudd CD. Corrosion resistance of zinc-magnesium coated steel. Corrosion Sci 2007; 49 3669-95.

[55] Jeurgens LPH, Vinodh MS, Mittemajier EJ. Quantitative analysis of multi-element oxide thin films by angle-resolved XPS: Application to ultra-thin oxide films on MgAl substrates. Appl Surf Sci 2006; 253: 627-38.

[56] Wei $\beta$ J, Himmel HJ, Fischer RA, Wöll C. Self-terminated CVDFunctionalization of Organic Self-Assembled Monolayers (SAM) with Trimethylamine Alane (TMAA). Chem Vap Deposition 1998; 4: 17-21.

[57] Unigovski YB, Gutman EM. Surface morphology of die-cast Mg alloy. Appl Surf Sci 1999; 153: 47-52.

This is an open access article licensed under the terms of the Creative Commons Attribution Non-Commercial License (http://creativecommons.org/licenses/by-nc/ 3.0/) which permits unrestricted, non-commercial use, distribution and reproduction in any medium, provided the work is properly cited. 